\title{
Analysis of Slotted Counter Sunk (35NCD16 Steel) Aerospace Fasteners
}

\author{
A R Abelin Roy \\ Deptt. of ME, \\ Govt. Engineering College, \\ Thrissur, India
}

\author{
Christopher Solomon S \\ MMD \\ VSSC, ISRO \\ Thiruvananthapuram, India
}

\author{
T Krishnakumar \\ Deptt. of ME, \\ Govt. Engineering College, \\ Thrissur, India
}

\begin{abstract}
Fasteners form the integrating elements of any aerospace hardware and provide the required mechanical integrity. Various types of fasteners including screws, rivets, bolts, pins, blind rivets, blind bolts, anchor nuts, solid inserts, collars etc. are used in aerospace application. Aerospace fasteners needs to be more durable, lighter and shall withstand high loads, vibrations and hostile environments such as deep space etc. In order to achieve this, aerospace fasteners are processed through specialized forging, heat treatment and thread rolling. Finite element analysis is done simulating the tensile testing of slotted counter sunk head screws and experiments are also conducted to verify the analysis results. A comparison is made on the stress distribution contours of slotted 120 degree countersunk head screw and slotted 90 degree countersunk head screw.
\end{abstract}

Keywords: fasteners; aerospace; countersunk; screws; stress distribution; finite element analysis;

\section{INTRODUCTION}

Joining by mechanical fasteners is common in assembly of structural components. The most important elements in structures (especially aerospace structures) are bolted joints, which are used in very large numbers on modern aircraft nowadays.

The $35 \mathrm{NCD} 16(3.5 \mathrm{Ni}-1.5 \mathrm{Cr}-0.5 \mathrm{Mo})$ steel in hardened and tempered condition is widely used as fasteners in aerospace structures. The $35 \mathrm{NCD} 16$ steel is used for making fasteners meeting the specified axial tensile stress rating of $1250 \mathrm{MPa}$.

Slotted 120 degree CSK and slotted 90 degree CSK fasteners are tensile tested for evaluating the UTL. Analysis is carried out using a finite element analysis software Abaqus by importing a solid model of the specimen created in CATIA. A comparison is made on stress distribution and breaking loads of slotted countersunk fasteners by FE analysis.

\section{MATERIAL}

The $35 \mathrm{NCD} 16$ is a high strength, low alloy vacuum arc remelted steel that takes its name from French industry designation. The combination of high strength, toughness and superior cleanliness available with $35 \mathrm{NCD} 16$ VAR steel readily identify it as a candidate for aerospace structural applications. The chemical composition of 35NCD16 is given in Table 1.

Table 1. Chemical Composition[2]

\begin{tabular}{|l|l|l|l|l|l|l|}
\hline & $\mathbf{C}$ & $\mathbf{M n}$ & $\mathbf{S i}$ & $\mathbf{N i}$ & $\mathbf{C r}$ & $\mathbf{M o}$ \\
\hline Spec & $0.30-$ & $0.30-$ & $0.15-$ & $3.50-$ & $1.60-$ & $0.35-$ \\
& 0.40 & 0.60 & 0.40 & 4.20 & 2.00 & 0.60 \\
\hline
\end{tabular}

\section{SOLID MODELING}

Modelling was done using CATIA V5.0. Slotted CSK head screws of dimensions M3, M4, M5 and M6 were modelled for both 120 degree and 90 degree types.

A typical solid model of a slotted 120 degree CSK screw is shown in figure 1 .

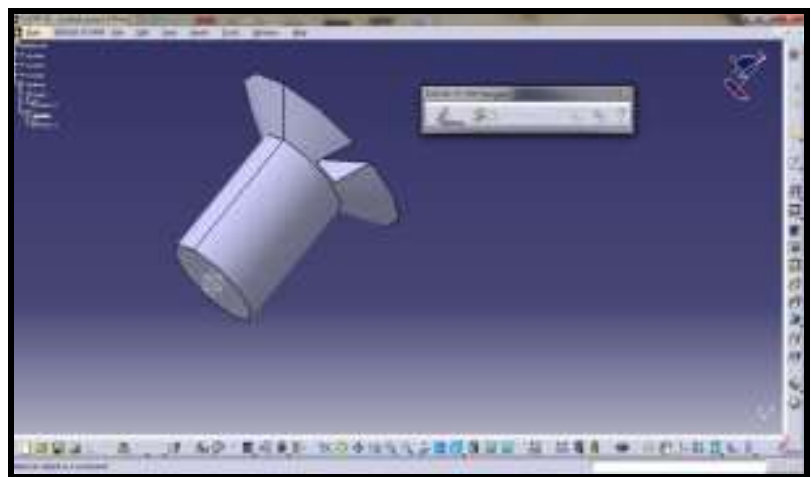

Figure 1. Screw modeled using CATIA V5.0

\section{FINITE ELEMENT ANALYSIS}

Finite element method (FEM), one of the most accurate numerical solution methods, has been increasingly used for modelling operations. It gives accurate results and therefore, it is now a well-accepted numerical method.

Slotted CSK screws modelled and saved as STEP format using CATIA V5.0 were imported to ABAQUS/CAE 6.10 for finite element program and divided into finite elements.

The screws were regarded as having linear elastic isotropic properties and its values were entered through material properties icon. The stress strain data are entered as true stress and true plastic strain. The true stress and true plastic strain were calculated as shown below.

To convert the nominal stress to true stress, use the following equation

$$
\sigma_{\text {true }}=\sigma_{\text {nom }}\left(1+\epsilon_{\text {nom }}\right)
$$

To convert the nominal strain to true strain, use the following equation

$$
\epsilon_{\text {true }}=\ln \left(1+\epsilon_{\text {nom }}\right)
$$

To calculate the modulus of elasticity, divide the first nonzero true stress by the first nonzero true strain.

$$
\text { Young's Modulus, } E=196589 \mathrm{~N} / \mathrm{mm}^{2}
$$


To convert the true strain to true plastic strain, use the following equation

$$
\epsilon_{\text {plastic }}=\epsilon_{\text {true }}-\frac{\sigma_{\text {true }}}{E}
$$

The tabulated results are as follows.

Table 2. True stress and Plastic strain tabulation.

\begin{tabular}{|c|c|c|c|c|c|c|}
\hline $\boldsymbol{\sigma}_{\text {nom }}$ & $\boldsymbol{\epsilon}_{\text {nom }}$ & $\begin{array}{l}1+ \\
\boldsymbol{\epsilon}_{\text {nom }}\end{array}$ & $\boldsymbol{\sigma}_{\text {true }}$ & $\boldsymbol{\epsilon}_{\text {true }}$ & $\frac{\boldsymbol{\sigma}_{\text {true }}}{\boldsymbol{E}}$ & $\boldsymbol{\epsilon}_{\text {plastic }}$ \\
\hline 0 & 0 & 1 & 0 & 0 & 0 & 0 \\
\hline 1169 & 0.006 & 1.006 & 1176 & 0.0059 & 0.0059 & 0 \\
\hline 1200 & 0.008 & 1.008 & 1209 & 0.0079 & 0.0061 & 0.0018 \\
\hline 1225 & 0.010 & 1.010 & 1237 & 0.0099 & 0.0062 & 0.0036 \\
\hline 1250 & 0.017 & 1.017 & 1271 & 0.0168 & 0.0064 & 0.0103 \\
\hline 1275 & 0.029 & 1.029 & 1311 & 0.0285 & 0.0066 & 0.0219 \\
\hline 1300 & 0.046 & 1.046 & 1359 & 0.0449 & 0.0069 & 0.0380 \\
\hline 1325 & 0.089 & 1.089 & 1442 & 0.0852 & 0.0073 & 0.0779 \\
\hline 1329 & 0.121 & 1.121 & 1489 & 0.1142 & 0.0075 & 0.1066 \\
\hline
\end{tabular}

Boundary conditions were applied by fixing head portion of the screw and tensile load was applied on the base of the screw as uniformly distributed load along the fastener axis as shown in fig. 2.

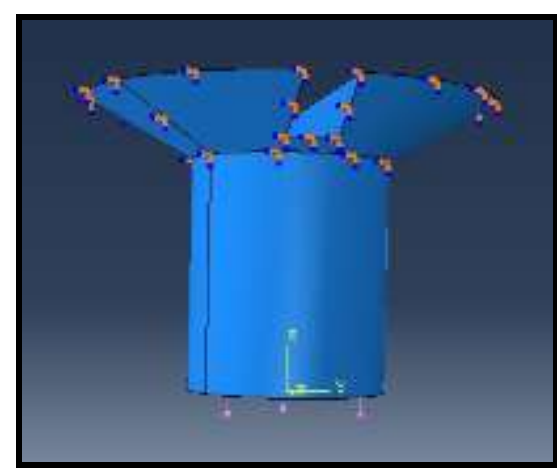

Figure 2. Modeled screw subjected to UDL along the axis.

Specified Ultimate tensile load $=$ UTS $\mathrm{x}$ Tension Cross-section Area

Table 3. Minimum Tensile Load at CSK head[1].

\begin{tabular}{|c|c|c|}
\hline $\begin{array}{c}\text { Thread } \\
\text { diameter } \\
(\mathbf{m m})\end{array}$ & Pitch & $\begin{array}{c}\text { Minimum Tensile } \\
\text { load at } \\
\text { CSK head }(\mathbf{K N})\end{array}$ \\
\hline 3 & 0.5 & 5.0 \\
\hline 4 & 0.7 & 8.8 \\
\hline 5 & 0.8 & 14.2 \\
\hline 6 & 1.0 & 20.1 \\
\hline
\end{tabular}

3 dimensional 4 node tetrahedron structural solid element (C3D4) with linear displacement behaviour was used as the element type. A mesh sensitivity study was conducted before selecting the final mesh and element size. A uniform finer mesh was used throughout the length of slotted CSK screw. A typical screw model after meshing is shown in Fig. 3.

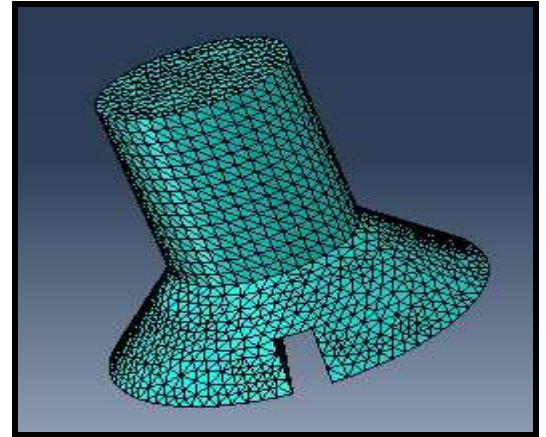

Figure 3. Meshed Model.

\section{MATERIAL TESTING}

Samples of fasteners were tension tested in Universal Testing Machine and the breaking load was noted. The fracture of fasteners during tensile test for all $120 \mathrm{deg}$ CSK head occurred only in the head and for all 90 deg CSK head occurred in the thread. Loading is done parallel to fastener axis.

The breaking loads were tabulated from the tension tests for Slotted 120 degree CSK and Slotted 90 degree CSK for different sizes. Five samples of Slotted 120 degree and 90 degree CSK screws were tension tested. Average values of breaking loads obtained are shown in Table 6 .

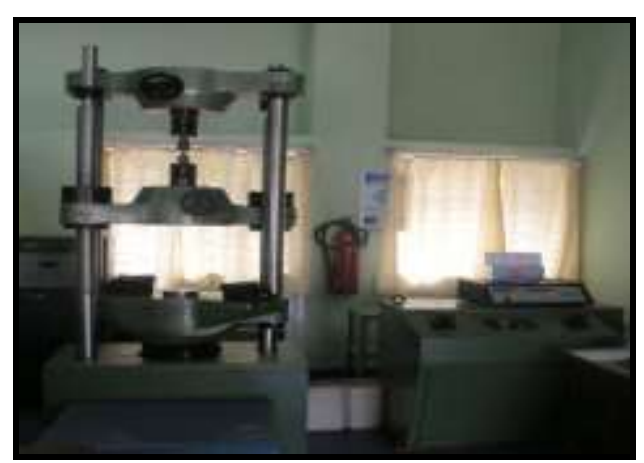

Figure 4. Tension testing of fasteners using Universal Testing Machine.

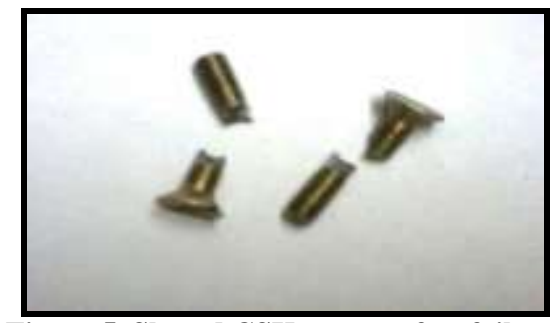

Figure 5. Slotted CSK screws after failure.

\section{RESULTS AND DISCUSSIONS}

The fracture of fasteners during tensile test occurred in the head-shank portion for $120 \mathrm{deg}$ CSK fasteners while $90 \mathrm{deg}$ CSK fasteners failed along the thread. The finite element analysis using Abaqus also shows presence of maximum value of stress in the shank or thread portion. Maximum stress as expected develops along the least area. In figure, red portion shows the maximum principal stress developed. For same load and same dimension of Slotted screws, 120 degrees and 90 degrees shows variations in stress distribution. The maximum principal stress developed in 120 degree CSK screws are much higher compared to 90 degree CSK screws. Pressure load 
corresponding to slotted 90 degree CSK screws applied in tension testing was given in FE analysis.

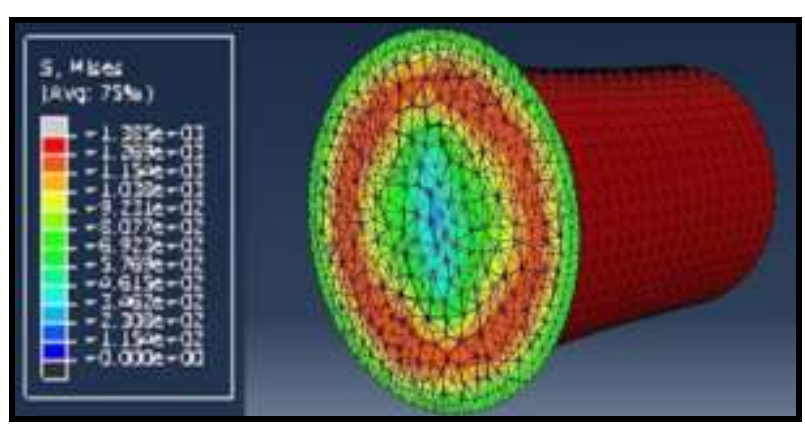

Figure 6. Slotted 90 degree CSK Head Screws at breaking load (Dimension: M3, Applied Load = 1109 N/mm²)

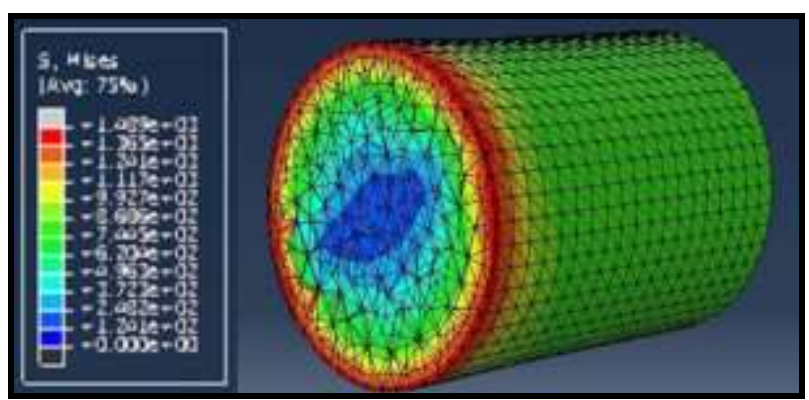

Figure 7. Slotted 120 degree CSK Head Screws at breaking load (Dimension: M6, Applied Load = 1109 $\mathrm{N} / \mathbf{m m}^{2}$ )

\section{LOAD-DISPLACEMENT RESULTS}

Table 4. M3 Slotted CSK Head screw.

\begin{tabular}{|c|c|c|}
\hline \multirow{2}{*}{ Load (KN) } & \multicolumn{2}{|c|}{ Displacement (mm) } \\
\cline { 2 - 3 } & 90 degree CSK & 120 degree CSK \\
\hline 0.00 & 0.0000 & 0.0000 \\
\hline 0.12 & 0.0004 & 0.0005 \\
\hline 0.48 & 0.0020 & 0.0023 \\
\hline 1.30 & 0.0053 & 0.0063 \\
\hline 2.13 & 0.0088 & 0.0104 \\
\hline 2.96 & 0.0124 & 0.0148 \\
\hline 3.79 & 0.0162 & 0.0198 \\
\hline 4.61 & 0.0204 & 0.0258 \\
\hline 5.44 & 0.0249 & 0.0335 \\
\hline 6.27 & 0.0424 & 0.0603 \\
\hline 6.90 & 0.1413 & 0.1882 \\
\hline
\end{tabular}

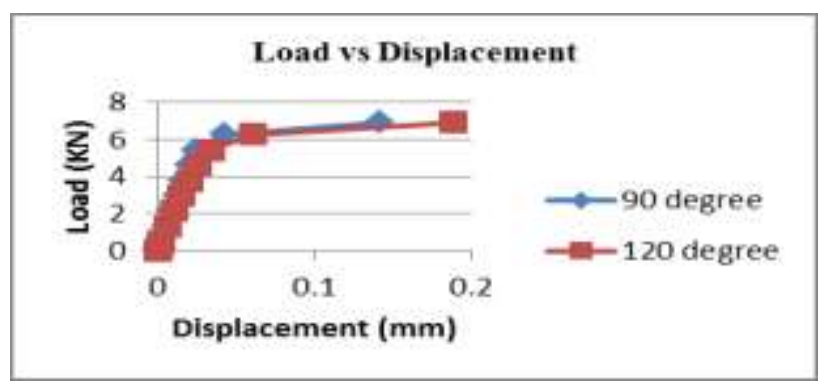

Figure 8. Load-displacement plot for M3 Slotted CSK screw.
Table 5. M4 Slotted CSK Head screw.

\begin{tabular}{|c|c|c|}
\hline \multirow{2}{*}{ Load (KN) } & \multicolumn{2}{|c|}{ Displacement (mm) } \\
\cline { 2 - 3 } & Slotted 90 & Slotted 120 \\
\hline 0.00 & 0.0000 & 0.0000 \\
\hline 0.48 & 0.0013 & 0.0015 \\
\hline 1.15 & 0.0031 & 0.0036 \\
\hline 2.22 & 0.0060 & 0.0070 \\
\hline 3.28 & 0.0089 & 0.0104 \\
\hline 4.34 & 0.0120 & 0.0140 \\
\hline 5.41 & 0.0151 & 0.0177 \\
\hline 7.53 & 0.0217 & 0.0268 \\
\hline 8.60 & 0.0255 & 0.0324 \\
\hline 9.66 & 0.0295 & 0.0394 \\
\hline 10.63 & 0.0374 & 0.0524 \\
\hline
\end{tabular}

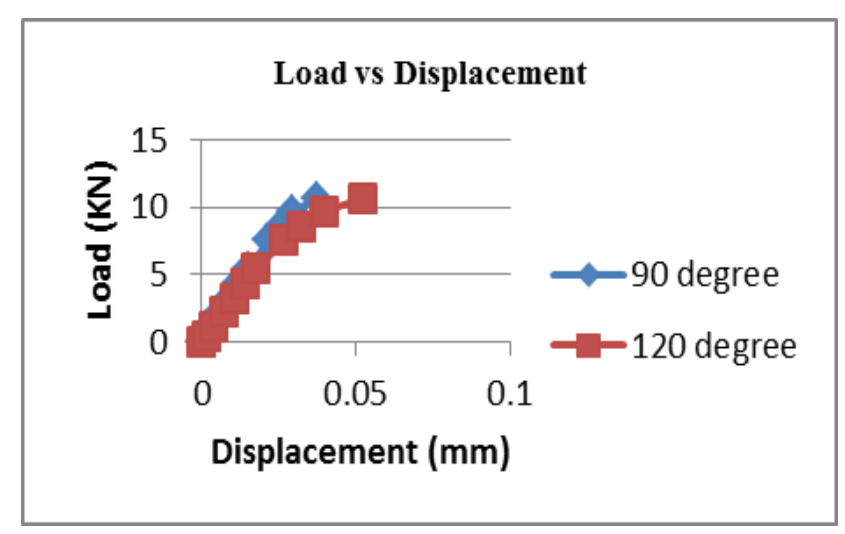

Figure 9. Load-displacement plot for M4 Slotted CSK screw

Table 6. M5 Slotted CSK Head screw.

\begin{tabular}{|c|c|c|}
\hline \multirow{2}{*}{ Load (KN) } & \multicolumn{2}{|c|}{ Displacement (mm) } \\
\cline { 2 - 3 } & 90 degree CSK & 120 degree CSK \\
\hline 0.00 & 0.0000 & 0.0000 \\
\hline 0.48 & 0.0011 & 0.0013 \\
\hline 1.19 & 0.00273 & 0.0033 \\
\hline 2.78 & 0.0063 & 0.0077 \\
\hline 4.80 & 0.0110 & 0.0133 \\
\hline 6.82 & 0.0156 & 0.0192 \\
\hline 8.84 & 0.0205 & 0.0253 \\
\hline 10.85 & 0.0256 & 0.0322 \\
\hline 12.87 & 0.0311 & 0.0401 \\
\hline 14.89 & 0.0370 & 0.0497 \\
\hline 16.81 & 0.0444 & 0.0634 \\
\hline
\end{tabular}




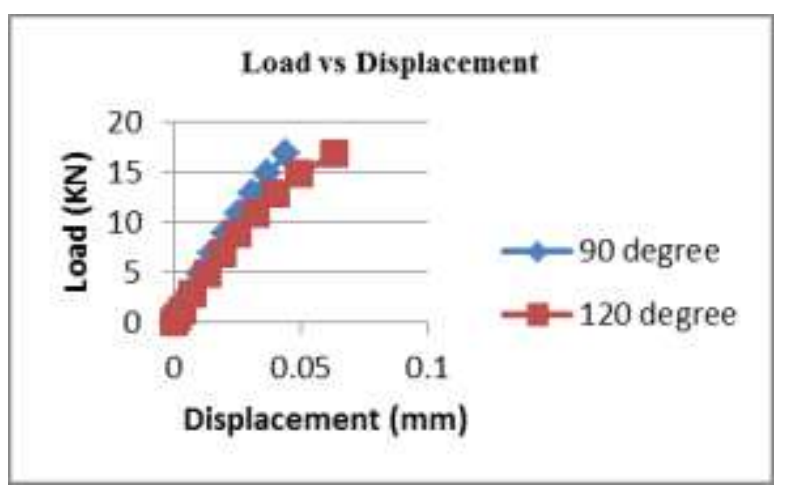

Figure 9. Load-displacement plot for M5 Slotted CSK screw.

Table 7. M6 Slotted CSK Head screw.

\begin{tabular}{|c|c|c|}
\hline \multirow{2}{*}{ Load (KN) } & \multicolumn{2}{|c|}{ Displacement (mm) } \\
\cline { 2 - 3 } & 90 degree CSK & 120 degree CSK \\
\hline 0.00 & 0.0000 & 0.0000 \\
\hline 0.22 & 0.0004 & 0.0005 \\
\hline 0.64 & 0.0013 & 0.0016 \\
\hline 1.58 & 0.0032 & 0.0039 \\
\hline 3.69 & 0.0076 & 0.0093 \\
\hline 6.81 & 0.0140 & 0.0171 \\
\hline 9.93 & 0.0207 & 0.0254 \\
\hline 13.05 & 0.0275 & 0.0347 \\
\hline 16.17 & 0.0349 & 0.0455 \\
\hline 19.30 & 0.0429 & 0.0587 \\
\hline 22.29 & 0.0513 & 0.0765 \\
\hline
\end{tabular}

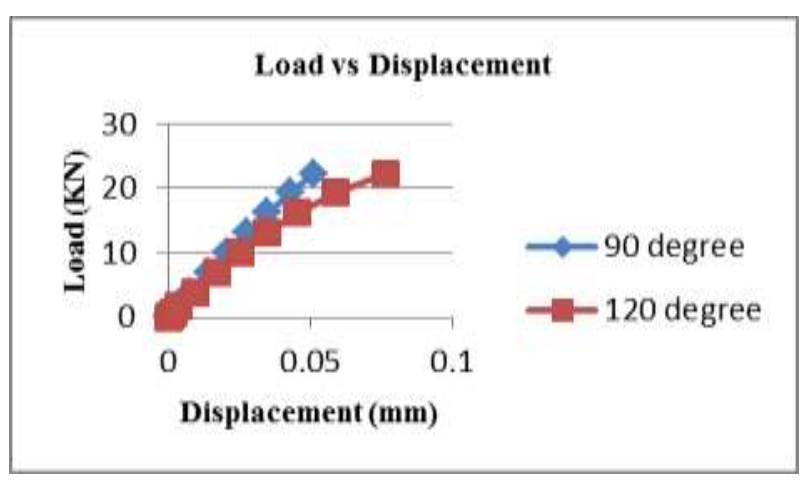

Figure 10. Load-displacement plot for M6 slotted CSK screw.

Slotted 120 degree screws showed higher displacements compared to Slotted 90 degree CSK screws and there was a www.ijsea.com steady increase in displacement values as for higher dimensions. Fig. 7 shows that for M3 displacement values for 120 degree and 90 degree CSK are closer while in fig.10, a higher gap can be noticed between the two.

\section{COMPARISON OF FEA RESULTS WITH MECHANICAL TESTING}

Table 8. Calculation of breaking load from FEA

\begin{tabular}{|l|l|l|l|l|}
\hline & M3 & M4 & M5 & M6 \\
\hline $\begin{array}{l}\text { Breaking load for 90 } \\
\text { degree (tension test) (KN) }\end{array}$ & 6.91 & 10.64 & 16.82 & 22.30 \\
\hline $\begin{array}{l}\text { Tensile pressure load for } \\
90 \text { degree screws (N/mm²) }\end{array}$ & 1373 & 1211 & 1189 & 1109 \\
\hline $\begin{array}{l}\text { Breaking load for 120 } \\
\text { degree (tension test) (KN) }\end{array}$ & 3.38 & 8.04 & 11.99 & 14.85 \\
\hline $\begin{array}{l}\text { Tensile pressure load for } \\
120 \text { degree screws N/mm }\end{array}$ & 671 & 915 & 844 & 738 \\
\hline $\begin{array}{l}\text { Tensile pressure load } \\
\text { values for 120 degree } \\
\left.\text { screws from FEA(N/mm }{ }^{2}\right)\end{array}$ & 744 & 927 & 895 & 796 \\
\hline $\begin{array}{l}\text { Breaking Load for 120 } \\
\text { degree from FEA (KN) }\end{array}$ & 3.74 & 8.13 & 12.70 & 15.99 \\
\hline
\end{tabular}

Table 8. showed that both the breaking loads obtained by mechanical testing and finite element analysis were close even though the values obtained by FEA were slightly higher.

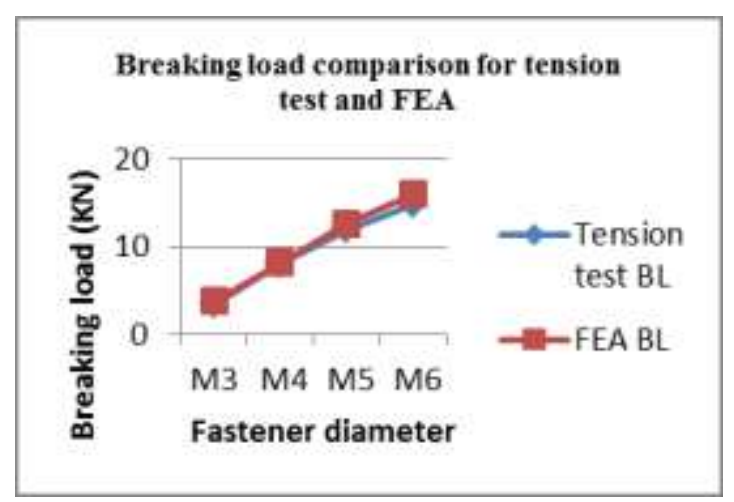

Figure 11. Tension test and FEA comparison.

Fig. 11 confirmed that the finite element analysis and mechanical testing done have a good correlation.

\section{CONCLUSIONS}

Even though a lot of researches regarding the material used (35NCD16 steel) for fasteners have been done, only few studies were reported on CSK screws. This paper attempts a detailed study on the finite element analysis of Slotted Counter Sunk Head Screws. 
(1) Analysis of Slotted Counter Sunk Head Screws revealed deformation across the cross section on applying uniaxial tensile load.

(2) An increase in Displacement values for Slotted 120 degree CSK head screws have been found compared to Slotted 90 degree CSK head screws for same dimensions and same load.

(3) Failure occurs at head to shank portion by uniaxial tensile test which is supported by the analysis where maximum stress is shown to be developed at same region.

(4) The uniaxial tension test results confirm breaking load needed for Slotted 90 degree CSK head screws are higher than Slotted 120 degree CSK head screws.

\section{ACKNOWLEDGMENTS}

Authors are thankful to the Vikram Sarabhai Space Centre, Indian Space Research Organisation, Thiruvananthapuram and Government Engineering College,
Thrissur for providing facilities for research and conducting experiments.

\section{REFERENCES}

[1] Sreekumar K, Arumugam M, Mohan S, Raghavan P, Rohit Kumar Gupta. Specification document for Bolts and Screws, VSSC, Feb 2007

[2] Abhay K. Jha, K. Sreekumar a, M.C. Mittal b, P.P. Sinha. Failure of $35 \mathrm{NCD} 16$ steel fastener - A metallurgical investigation

[3] Abhay K Jha, P Ramesh Narayanan, K Sreekumar, M C Mittal, K N Ninan Hydrogen embrittlement of 3.5Ni-1.5Cr-0.5Mo steel fastener, June 2007

[4] Abhay K. Jha , Satish Kumar Singh, M. Swathi Kiranmayee, K. Sreekumar, P.P. Sinha, Failure analysis of titanium alloy (Ti6Al4V) fastener used in aerospace application, 1 June 2010

[5] K.R. Mohan Ananthanarayanan and A.R. MuraliSankar, Case study on the failure analysis of fasteners used for aerospace applications, Dec 2009. 